http://dx.doi.org/10.12795/PH.1990.v05.i01.20

\title{
La «novela política» en el Perú: Cambio de guardia de Julio Ramón Ribeyro
}

$M^{a}$ Teresa Pérez Rodríguez

La vocación realista de la novela peruana es un hecho que parece confirmarse a medida que se acrecienta la tradición narrativa en el país. El más breve repaso por su historia literaria, desde la aparición en 1848 de la que se considera su primera novela, El Padre Horán, hasta la más reciente narrativa urbana de la generación del 50, nos confirma en la idea de esa constante voluntad de realismo. En los umbrales del género, un hecho real, el asesinato de un parroquiano por su confesor, le servía a Arístegui para desplegar en su obra una actitud francamente anticlerical y crítica a través de la descripción de la miserable vida de los habitantes del Cuzco. Esta novela marcaba, así, el signo crítico, nada gratuito, que la narrativa realista peruana iba a tener en lo sucesivo. A partir de entonces, la novela, primero costumbrista, de aliento indianista más tarde, con Clorinda Matto de Turner, regionalista y claramente indigenista después, no dejaría de percibir la realidad como problema que tenía que ser asumido.

La pretendidamente radical irrupción en el panorama literario nacional del grupo de los narradores del cincuenta no vino a cuestionar tampoco esa premisa fundamental; por el contrario, el deseo de no desvincualr la obra de la realidad que la suscita se convirtió en una de sus líneas unificadoras más importantes. Su novedad, por oposición a la literatura inmediatamente anterior, radica, de un lado, en la adopción de la ciudad como tema principal de sus narraciones; en su descubrimiento de Lima como urbe monstruosamente moderna, con sus profundas iniquidades y contradicciones. De otro, en la aventura de renovación y experimentación del lenguaje en la que se embarcan todos sus componentes, hastiados de ese, para ellos, realismo naturalismo característico de la novela anterior -opinión que puede, en general, suscribirse si no olvidamos la genial excepción que supone la obra de Arguedas.

Dentro de esta generación la trayectoria literaria de Julio Ramón Ribeyro es una de las más afortunadas y complejas por su continuidad (habría que indagar en 
profundidad el por qué del silencio editorial que, tras de una o dos publicaciones, se ha cernido sobre estos autores), pero también por su coherencia, por la elaboración de un universo autónomo que no hace sino enriquecerse con cada nueva creación.

La novela que comentamos no es una de las más frecuentadas por el corpus, injustamente escaso, de la crítica ribeyreana. Y, sin embargo, ofrece un campo enormemente interesante para indagar en el sentido raigalmente comprometido de la narrativa peruana, hasta tal punto que esa necesidad de testimoniar la realidad social ha tenido -sin duda porque la situación caótica del país así lo exigía- un carácter excluyente y casi fatal.

A. Cornejo Polar ya había llamado la atención sobre este carácter cuando, a finales de los setenta, se atrevía a vislumbrar un inicial resquebrajamiento del largo y todopoderoso imperio del realismo ${ }^{1}$. Aludía entonces a ciertas vertientes -lo real maravilloso, la ficción científica- cultivadas por autores como E. González Viaña, M. Scorza, J. B. Adolph o J. E. Eielson, a quienes veía inclinarse más hacia el reino de la imaginación. Si algún interés puede tener este artículo, además de llamar la atención sobre la novela de Ribeyro, es el de plantear, ya a finales de los ochenta, si efectivamente la narrativa peruana se ha abierto hacia esas otras dimensiones en el arte del narrar o si ha seguido deslizándose por sus antiguos cauces, ya transitados.

Por lo pronto, hay que aclarar que no en todos los casos -de los citados por el profesor Cornejo Polar- esta nueva vía de escritura se traduce en una desvinculación de ese espíritu de testimonio crítico acerca de la realidad. Y la figura y la obra de M. Scorza, tan comprometidas con la reivindicación de la lucha de los campesinos andinos, resultan un claro ejemplo de ello. Su caso, dentro del circuito literario peruano, resulta paradigmático en más de un sentido, por cuanto la crítica del país ha llegado a censurarle que sus novelas eran una traición (!!) a la realidad. Sin duda, este inadmisible reproche (además de estar apoyado en una larga tradición realista) tiene su origen en una actitud equivocada ante la obra de arte. El crítico no debe tener como misión principal rastrear la parte que, dentro de la ficción, toca a la realidad porque ello significa olvidar una premisa fundamental, a saber, que la obra literaria implica, para convertirse en obra de arte, una reelaboración artística de la realidad que actúa como referente. Lo cual no quiere decir que por ello deje de ser un testimonio fidedigno y válido sobre esa misma realidad.

$\mathrm{Y}$ al tocar este tema de las relaciones entre la realidad y el producto literario hemos llegado a una de las tensiones que subyacen en la narrativa toda de Julio Ramón Ribeyro. Nos referimos a su posición optimista frente al hecho literario al que confiere un papel testimonial y de denuncia. Unas palabras del propio autor -referidas a su cuentística pero que podemos hacer extensibles a toda su obra- nos muestran con claridad esta actitud:

Mis cuentos sólo pretenden enfocar determinadas situaciones -exactas o verosímiles- de nuestra realidad, sin permitir acerca de ella algún juicio explícito. No es

1 «Altemativas al realismo en la narrativa peruana contemporánea», en XVII Congreso del Instituto Internacional de Literatura Iberoamericana, (1978), p. 1.014. 
dificil, sin embargo, discernir hasta qué punto me solidarizo con ella. En el fondo de toda pintura realista hay un no-conformismo y como el germen de una crítica ${ }^{2}$.

Y esa crítica que sustenta todo su universo narrativo, aparece, descarnada esta vez y terriblemente certera, en Cambio de guardia, publicada en 1976 pero escrita en París, entre los años 1964 y 1966. La novela nos resulta de especial interés por más de un motivo. En primer lugar porque puede discutirse su inclusión dentro de la tipología de las novelas del dictador; nos ofrece además el escenario perfecto para el estudio de las vinculaciones entre literatura y sociedad y representa, en fin, una variación en el modo de narrar a que Ribeyro nos tenía acostumbrados. Vayamos por partes.

En las notas que acompañan a la novela, una del propio autor y otra de Washington Delgado, se insiste en la precisión cronológica, tanto para evitar posibles comparaciones con otras novelas que han tratado la corrupción de determinadas etapas de la política peruana, como atentiendo también a la previsible vinculación de los sucesos narrados con los hechos reales. Conversación en La Catedral, la alusión nos parece clara, aparece en 1969 y es un crudo reflejo de la corrupción del país en el ochenio odriísta. Cambio de guardia no se publicará sino diez años después de haber sido terminada y este simple accidente editorial puede perturbar, a juicio de W. Delgado, la apreciación crítica del libro, pues parecería una secuela de las novelas americanas que en los últimos años han tenido como tema las dictaduras militares en nuestro continente. Estas y otras sutilidades dejan entrever un exceso de celo por parte del prologuista para atenuar las semejanzas que la novela de Ribeyro pudiera tener con otras de su época. En todo caso, y si recordamos obras tan importantes para la configuración del género como El recurso del Método, Yo el Supremo y El otoño del Patriarca -aparecidas en los años 1974-75-, no hay por qué considerarla una «secuela» sino, y aun esto vamos a discutirlo en seguida, una manifestación más de este subgénero.

Si aceptamos para esta tipología la denominación, más abarcadora, de narrativa de la dictadura -pues no en todas las obras hay un análisis de la figura del tirano- la obra de J. R. Ribeyro podría tal vez ser incluida dentro de ella. (Entre los distintos hilos argumentales que se barajan en la novela, uno nos cuenta la historia de un «cuartelazo» que llega a feliz (!) término). Y, sin embargo, nos parece más correcta su adhesión a una denominación, más general, que aludiera a la «novela política» ${ }^{3}$. La confabulación de los militares, debidamente aconsejados por los socios norteamericanos, para derrocar al Presidente de la República constituye una de las líneas fundamentales de la trama pero no la única, ni la más importante.

Como es común entre las obras que integran la narrativa del dictador/dictadura, la novela incide en el concepto de poder y en los mecanismos que desencadena, para llevar a cabo un análisis profundo de la sociedad. La Historia es, sin lugar a dudas, el polo en el que convergen los distintos discursos narrativos. Mas sobre este polo, en las

2 J. R. Ribeyro, Prólogo a Los gallinazos sin plumas, (Lima, 19 ed., 1955).

${ }^{3}$ L. A. Sánchez en su libro Proceso y contenido de la novela hispanoamericana, (Madrid: Gredos, 1968), dedica un capítulo a «La novela política», dentro de la cual establece tres subgrupos: 1) caudillos, dictadores y tiranos; 2) la conspiración y la revolución; y 3) la prisión política. División que no se demuestra muy operativa puesto que, generalmente, la misma novela engloba, interrelacionados, todos estos temas. 
obras que integran dicho subgénero, se proyecta una perspectiva mítica que arroja una luz irreal, casi fantasmal, sobre los personajes. En Cambio de guardia esta atmósfera mítica no se respira por ninguna parte y, en consecuencia, al no existir esa mitificación tampoco tiene lugar el movimiento contrario: la caricaturización del (anti)héroe, su desmitificación. Nos parece que éste es un rasgo fundamental que distancia la novela de Ribeyro del conjunto de la narrativa del dictador. Por lo pronto, el de Ribeyro no puede ser considerado un «libro-símbolo» de la dictadura. Si hay en él alguna intención de universalidad desde luego no se manifiesta en las descripciones espaciales (nueva muestra de la novela urbana, la acción transcurre íntegra en los barrios y en las calles de Lima, a excepción de uno o dos episodios que se sitúan en la provincia) o cronológicas (referencia a personajes reales de la vida peruana que atan la novela a un determinado tiempo).

Mas como la realidad no es nunca clara y distinta, he aquí que pueden señalarse algunos puntos de convergencia. En efecto, si no hay una degradación sistemática, esperpéntica (como ocurre en la novela de Aguilera Malta El secuestro del general, 1974), sí que encontramos una veta irónica que impregna toda la novela y que, como técnica literaria, remite al mismo deseo de análisis profundo de la sociedad, ridiculizándola, sacando a la luz su faceta más sórdida. Y es en este punto donde entra en juego la personalidad del escritor Ribeyro. Lo suyo es la ironía, el fino humor, el hablar casi en sordina, sin estridencias y al margen de aventuras formales. Niega toda posibilidad heroica a sus personajes y los deja reducidos a lo que son -a lo que somos-: personas concretas insertas en un complejo entramado de circunstancias y motivaciones.

Las concomitancias que pueden señalarse tienen, unas veces, un sentido puntual -la aparición del fenómeno del espiritismo: la figura cómica del medium que propicia una situación esta vez sí esperpéntica y claramente divertida; o la presencia de los sueños proféticos- $\mathrm{y}$, en otras ocasiones, un carácter más estructural como es la recurrencia a todo el submundo prostibulario que, recordemos, era un elemento indispensable en la narrativa de la dictadura. En Cambio de guardia lo constatamos también y con la misma funcionalidad, la de destruir la (supuesta) dignidad de los altos mandos.

Se apunta, asimismo, otro aspecto sumamente caracterizador del tirano: la soledad. El generalote de turno, destinado a conducir a partir del golpe militar la nave del estado, siente miedo ante la hora decisiva y se refugia no en su mujer, pues ya conocemos su fracasada vida marital (¿hay en la narrativa de Ribeyro algún personaje felizmente casado?), sino en esa degradación de las relaciones humanas que determina el burdel.

Señalar estas similitudes no invalida la propuesta que hacíamos más arriba de entender la obra de Ribeyro como una novela política, al estilo de la de Vargas Llosa ${ }^{4}$. Y ello porque más que un análisis exhaustivo de los mecanismos del poder dictatorial, lo que ha interesado a nuestro autor es hacer un diagnóstico de la sociedad peruana a

${ }^{4}$ Por más que el autor haya negado que se trate exactamente de una novela política. (Reportaje, en Madrid, enero de 1970). 
través de unas cuantas vidas, reales o no -no nos interesa- mas, en todo caso, representativas y verosímiles -se ha dicho ya que la novela es el arte de lo posible.

Si bien el complejo fenómeno de las dictaduras, que hunde sus raíces en las guerras independentistas, es patrimonio común de todos los países hispanoamericanos, en la historia del Perú tenemos uno de los ejemplos más aventajados. A Salaverry y Gamarra, personificación del militarismo postindependentista, le siguen las figuras de Nicolás de Piérola (1895-1899); J. Pardo (1903-1932). Después del asesinato de este general se suceden una serie de meteóricos gobiernos hasta llegar a la entronización del mariscal O. R. Benavides (1933-1939); M. Prado (1939-1945); el ochenio de M. A. Odría (1948-1956); la experiencia reformista o revolucionaria, según se la quiera tipificar, del Gobierno Militar de J. Velasco Alvarado (1968-1975); el gobierno también militar de F. Morales Bermúdez (1975-1980).

Con estos antecedentes, y con el carácter realista que hemos venido señalando para la novela peruana, no es de extrañar que el panorama literario en relación al tema sea uno de los más fecundos del continente.

Como antecedente de esta narrativa política puede citarse la obra de Mercedes Cabello Carbonera El Conspirador (Autobiografía de un hombre público. Novela político-social), aparecida en 1882, a la que sigue toda una larga lista de autores, quizá justamente olvidados, y unas cuantas obras de interés literario. El novelista ha mirado siempre la realidad pero no en todos los casos esa realidad ha sufrido el proceso de transfiguración que convierte tal simulación en una realidad simbólica. Así, hay textos (como el citado de M. Cabello Carbonera, el de F. Panizo, El dictador del Perú. Tomás Gutiérrez o la víctima de la ambición, 1872, C. Falcón, Pueblo sin Dios y muchos otros) que difícilmente pueden considerarse novelas y que tienen más bien un carácter puramente documental.

Se diría que la literatura peruana ha luchado siempre entre esa intromisión cruda de los datos de la realidad y la incapacidad para transfigurarlos artísticamente.

Volviendo la mirada al panorama literario de los últimos años constatamos que la literatura peruana sigue invocando un renovado realismo, pero ya ese salto cualitativo, definitivamente, se ha logrado.

En 1973 aparecían Las rayas del tigre de G. Thorndike y La ronda de los generales de J. Adolph; en 1976 No, mi general del primero de los autores citados y Cambio de guardia. La realidad entraba de nuevo por los resquicios de la novela pero ahora para integrarse en un mundo tan complejo y auténtico, al menos, como la vida misma. Un sentimiento de insatisfacción profunda se desprende de todas ellas (y habría que añadir aquí Conver sación en La Catedral) y ninguna consigue responder a ese interrogante que Zavalita sigue planteando en el eco del lector: ¿En qué momento se jodió el Perú?

Cambio de guardia, novela tremendamente antimilitarista y anticlerical, es un amargo análisis de la realidad peruana. Ya sabemos que no es posible una mirada aséptica y la de Ribeyro está tamizada por la ironía y por un profundo escepticismo. Esa realidad parece identificarse con el período de la «Revolución Restauradora» que llevó a Odría a la presidencia del país, mas esto resulta secundario porque el propósito del autor era, con sus palabras, profundizar en las constantes más visibles de nuestra sociedad o de cualquier sociedad latinoamericana. Esta pretensión de universalidad 
(y de la intemporalidad que ella conlleva) es lo que le movió finalmente a publicar una novela que consideraba anacrónica.

Dentro del corpus de la narrativa ribeyreana esta obra introduce más de un elemento novedoso. Por lo pronto, es la única producción entre las suyas que no parte de alguna experiencia personal, sino que responde, más bien, a ciertas ideas abstractas a las que el autor quiso dar un carácter demostrativo.

Asimismo, resulta original la disposición de la intriga y los recursos técnicos que se emplean. La novela está dividia en trece partes, compuestas cada una de ellas por una serie de breves secuencias numeradas (186 en total). Se vale del recurso de la fragmentación y de la simultaneidad para cristalizar esa concepción del mundo que sustenta la obra. Hay, al menos, ocho historias que se entrecruzan de modo que los personajes, aún sin saberlo, se ven inmersos en una red tejida, en parte, por ellos mismos y para otros. Hablábamos antes de Ribeyro como escritor que había permanecido ajeno a las aventuras formales que caracterizan a la nueva novela hispanoamericana y de ahí que el propio autor se haya referido a la composición de la novela como «ensayo ocasional». Aparte de que en algunos de sus cuentos podemos rastrear una técnica parecida, nos parece que el autor sigue aquí siendo fiel a sí mismo y a su escritura. Lo reconocemos en ese acendrado escepticismo del narrador, en el espíritu derrotado de sus criaturas, incapaces de llegar hasta el final en su lucha, autoconvencidos, a mitad del camino, para no tener que dar el gran salto final. Los tímidos rebeldes de Cambio de guardia se niegan a sí mismos y al futuro toda esperanza de cambio y se rinden al nuevo orden presidido por el General Chaparro.

La novela, que se articula en función de dos dicotomías fundamentales: pacto/ traición y deseo/claudicación, nos enfrenta a un mundo multiforme, de leyes a veces incomprensibles, regido por el azar; un mundo que el lector no logra penetrar en su totalidad, puesto que hay hechos que quedan en una desesperante ambigüedad. Y para la expresión de este universo era necesaria esa visión caleidoscópica y fragmentaria que hemos constatado en la novela. Cada obra, nos parece, exige su técnica y, en este caso, es un acierto de Ribeyro el haber sabido encontrar la adecuada.

Queda fuera de los límites de este artículo intentar un análisis más detenido de la novela; me limitaré por ello a insistir en la validez del disgnóstico que hace de la realidad peruana por más que el autor haya insistido en considerarla una obra anacrónica y haya aceptado su publicación sólo con el convencimiento de que las sociedades tienden a veces a efectuar movimientos pendulares o circulares y en estas circunstancias lo pasado puede ser lo futuro, lo presente lo olvidado y lo posible lo real ${ }^{5}$.

Hemos visto cómo, a partir de la década de los cincuenta, la literatura se sumó al proceso de transformación (epidérmica más que real) y modernización del país; asumiendo como reto la configuración de la obra literaria como organización linguiístico-formal, pero siempre atenta a la problemática que su sociedad les ofrecía.

A partir de 1983 la violencia, que era la atmósfera narrativa de muchos autores de aquella generación, se ha desatado, creando un clima de inestabilidad política y de

5 «Nota del autor» a Cambio de guardia, (Lima: Milla Batres, 1976), p. 9. 
inseguridad ciudadana. Las acciones terroristas de Sendero Luminoso y del Movimiento Revolucionario Tupac Amaru, la actuación represiva del Ejército y también, en las zonas rurales, la aparición de los Ronderos, bandas armadas de las comunidades campesinas para defenderse del terrorismo y del pillaje, conforman una atmósfera cada vez más enrarecida y agravada aún, si cabe, por la dependencia económica y la situación internacional.

Con la subida al poder de Alán García, Secretario General del APRA, por primera vez en la historia del Perú un proyecto político, progresista y de neta raíz popular, se alza democráticamente con la presidencia del país. A este intento de proyecto nacional de la izquierda se suma la mayoría de los escritores jóvenes. Una literatura tan vinculada a la realidad como la peruana no podía permanecer al margen de tan graves acontecimientos. Y es así que puede constatarse el afianzamiento de una línea narrativa sustentada en el marxismo que enriquece el relato social, otorgándole una perspectiva popular. Autores ligados al grupo Narración, como Antonio Gálvez Ronceros, Augusto Higa o Roberto Reyes y otros, más jóvenes, como Luis Urteaga, Gregorio Martínez, Omar Arnes o Cronwell Jara son los representantes de esta nueva línea narrativa que privilegia la oralidad e incorpora también el ambiente de los negros peruanos. En todos, esa misma preocupación por renovar la narrativa, que aparece también en Alforja de ciego de J. Díaz Herrera, 1979, y que constituye uno de los aspectos más interesantes del ámbito literario nacional.

Esta es, claro está, una vía dentro de un panorama mucho más rico, pero algo confuso. Y sin duda el débil, y hasta segregador, sistema editorial peruano tiene mucho que ver en esta falta de nitidez. Temáticamente el mundo andino sigue interesando a un importante número de escritores peruanos (la pentalogía de Scorza, Cusco, crónica de una pasión de A. Avendaño) que transmiten a su obra una gran carga ideológica. Se constata también la aparición de la novela de entretenimiento, al lado de una novela histórica.

Sin duda, la narrativa peruana atraviesa hoy por un buen momento pero son pocos los autores que han ingresado en el circuito interancional y son fácilmente accesibles para el público europeo -además de Vargas Llosa, M. Scorza, BryceEchenique y, poco a poco, J. R. Ribeyro, mas ello al precio de la emigración. 
